\title{
Damage thresholds and population dynamics of Pratylenchus penetrans on carrot (Daucus carota L. cv. Nerac) at three different seed densities
}

\author{
Misghina G. Teklu • Beira H. Meressa • \\ Esther Radtke • Thomas H. Been • \\ Johannes Hallmann
}

Accepted: 8 March 2016/Published online: 17 March 2016

(C) The Author(s) 2016. This article is published with open access at Springerlink.com

\begin{abstract}
Yield and quality loss of carrot (Daucus carota L. cv. Nerac) caused by Pratylenchus penetrans and the population dynamics of this nematode were studied in a climate controlled glasshouse. A range of 12 nematode densities was used at three different seed densities of carrot; 2, 4 and 18 seeds pot ${ }^{-1}$. Seinhorst's yield loss model; $y=m+(1-m) 0.95^{P i / T-1}$ for $P i>T$, $y=1$ for $P i \leq T$ for Tylenchina was fitted to the yield and quality loss data. Seinhorst's model for population dynamics of migratory nematodes with multiple generations; $P f=M^{*} P i /(P i+M / a)$ was fitted to the data of the final population densities $(P f)$. P. penetrans had a significant impact on carrot taproot yield and its quality. The tolerance limits for the relative carrot taproot yield $\left(T_{\mathrm{y}}\right)$ were $1.51,1.88$, and 1.37 and those of quality yields $\left(T_{\mathrm{q}}\right)$ were $0.67,0.18$, and 0.40 P. penetrans (g dry soil) ${ }^{-1}$
\end{abstract}

\footnotetext{
M. G. Teklu • T. H. Been

Agro-Systems Research, Wageningen University and Research Centre, 6700 AA Wageningen, The Netherlands

M. G. Teklu $(\bowtie)$

Laboratory of Nematology, Wageningen University, 6708

PD Wageningen, The Netherlands

e-mail: Misghina.goitomteklu@wur.nl

B. H. Meressa $\cdot$ J. Hallmann

Federal Research Centre for Cultivated Plants, Julius

Kühn-Institut, Institute for Epidemiology and Pathogen

Diagnostics, Toppheideweg 88, D-48161 Münster, Germany

E. Radtke

Landwirtschaftskammer Nordrhein-Westfalen,

Pflanzenschutzdienst Siebengebirgsstraße 200, D-53229 Bonn,

Germany
}

at 2, 4 and 18 seeds pot $^{-1}$, respectively. Both the minimum yield $(0.20,0.29$, and 0.60$)$ and the minimum quality yield $(0.05,0.07$, and 0.20$)$, expressed as a proportion, increased with seed density at 2, 4 and 18 seeds pot $^{-1}$, respectively. The model for population dynamics fitted well to the $P f$ data obtained. The maximum multiplication rates $(a)$ were $19.58,9.99$, and 17.54, while the maximum population densities $(M)$ were $49.86,43.21$, and 60.37 P. penetrans (g dry soil) ${ }^{-1}$ at 2,4 , and 18 seeds $\operatorname{pot}^{-1}$, respectively. Carrot cv. Nerac can be considered a good host for $P$. penetrans.

Keywords Lesion nematodes $\cdot$ Modelling $\cdot$ Population density · Quality loss · Tolerance limit and yield loss

\section{Introduction}

Carrot (Daucus carota L.) is a major vegetable grown in the temperate regions and cooler highlands of the tropics. Its production is affected, among others, by rootknot nematodes (Meloidogyne spp.), root-lesion nematodes (Pratylenchus spp.), pin nematodes (Paratylenchus spp.) and stubby root nematodes (Paratrichodorus spp.) (Noling 2012). In particular, infestation by Meloidogyne hapla, M. fallax and M. chitwoodi can lead to severe quality losses due to forking, stunting, excessive formation of lateral roots and galls on the carrot taproots (Wesemael and Moens 2008; Walker 2004; Heve et al. 2015).

In Germany, M. hapla was considered the most damaging plant-parasitic nematode on carrots, particularly 
on light sandy soils (Hahn 1958; Stein 1963; Gugino et al. 2006). Recently root-lesion nematodes (Pratylenchus spp.) seem to become one of the constraints of carrot production. A survey of cereal and vegetable production systems under organic farming in Germany revealed more than $90 \%$ of the samples being infested with Pratylenchus spp. (Hallmann et al. 2007). A similar survey in northern Tasmania, Australia revealed that 28 out of 33 carrot crops ( $c a .85 \%$ ) were found infested by Pratylenchus spp. as compared to only five out of 33 ( $\mathrm{ca}$. $15 \%$ ) by root-knot nematodes (Hay and Pethybridge 2005). Pratylenchus spp. are considered the third most economically important plant-parasitic nematodes in crop production (Castillo and Volvas 2007; Jones et al. 2013). Diverse adaptation has enabled Pratylenchus spp. to colonize plant species under different environmental conditions within the temperate and tropical zone (Potter and Olthof 1993; Castillo and Volvas 2007).

Generally, yield loss is experienced when population densities at planting are above the tolerance limit (Viaene and Abawi 1996; Schomaker and Been 2013). Yield reductions by $P$. penetrans on carrots and $P$. crenatus on Kuroda type carrots is reported by (Vrain and Belair 1981; Hay and Pethybridge 2005) respectively. Also, the quality of the carrot taproot is affected by $P$. penetrans. Quality losses due to forking of carrot taproots, stunted growth and excessive formation of lateral roots are reported (Coosemans 1975; Vrain and Belair 1981). Similar quality defects on carrot taproots are described for P. crenatus (Potter and Olthof 1993). Therefore, knowledge concerning the relation between $P i$ and expected yield and quality loss is of major importance to plan justifiable control strategies (Ferris 1978; Barker and Olthof 1976) to keep population densities below the 'economical' tolerance limit where unacceptable yield or quality losses are suffered (Seinhorst 1967, 1970).

Both in Germany and The Netherlands, carrots for industrial processing are grown only on fields that have been surveyed for $P$. penetrans infestations. Based on soil samples, a contract can be obtained when the nematode density detected is below a threshold of 100 and $75 \mathrm{P}$. penetrans $(100 \mathrm{ml} \mathrm{soil})^{-1}$ for the two countries, respectively. These thresholds are based on rough estimations, but generally provide for the absence of serious quality problems caused by $P$. penetrans. In the ProGemüse project (INTERREG IV-A II-3-04-100), a prototype sampling method has been developed to improve the accuracy of the population density estimate used for farmers advice, but information on the tolerance limit, yield and quality loss of carrots, and the population dynamics of $P$. penetrans at different seed densities is still lacking.

In carrot production, seed densities range from 1 to 20 million seeds $\mathrm{ha}^{-1}$, depending on their use either for processing or the fresh market. The seed density is used to determine the size of the carrot taproots produced. The objectives of this study were to determine both the damage thresholds for yield and quality loss of carrot cv. Nerac attacked by $P$. penetrans at different seed densities and its population dynamics. This information is required to help farmers, industrial grower and extension services in their decision making process as to whether a land is suitable for carrot production and if crop protection is needed based on pre-crop sampling results.

\section{Materials and methods}

This experiment was carried out at the Julius KühnInstitute, in Münster, Germany, while at the same time a similar experiment was conducted at Wageningen UR, Wageningen, The Netherlands with carrot cv. Nerac and M. chitwoodi (Heve et al. 2015).

\section{Multiplication of $P$. penetrans}

Three seeds pot $^{-1}$ of maize (Zea mays cv. Husar) were planted in 6-1 pots containing a bottom layer of $390 \mathrm{~g}$ of non-crushed hydro-grains and $5610 \mathrm{~g}$ of pre-glacial silver sand. The bottom of each pot was covered with Ederol filter No. 261, $15 \mathrm{~cm}$ diam. (J.H. Ritmeester B.V, Utrecht) to prevent the leaching of the growing medium. A $P i$ of 4 $P$. penetrans (g dry soil) ${ }^{-1}$ was inoculated by adding the required suspension in a shallow groove around the established plants after 2 weeks. The groove was then covered with soil. Pots were watered and fertilized every week for 90 days. Roots were then collected by sieving the soil through $3 \mathrm{~mm}$ mesh sieves. The collected roots were gently rinsed, cut into pieces of $1 \mathrm{~cm}$ and placed on extraction sieves 
$(150 \mu \mathrm{m}$ mesh size, diam. $20 \mathrm{~cm})$, and were placed on top of extraction dishes (diam. $25 \mathrm{~cm}$ ) and incubated in a Seinhorst mist-chamber (Seinhorst 1988). Nematodes were collected every 3 days from the roots of 45 maize plants until a stock suspension, containing sufficient $P$. penetrans (adults and juveniles) for the experiment (11.1 million) was obtained. The stock suspension was stored at $4{ }^{\circ} \mathrm{C}$ till the time of inoculation.

\section{Growth medium and pot preparation}

For this experiment a steam sterilized field soil was used. After steaming, the soil was exposed to the air for at least 30 days to enable evaporation and dissipation of toxic compounds. The pots used were slightly tapered with a square base of 9.8 by $9.8 \mathrm{~cm}$, a square top of 13.7 by $13.7 \mathrm{~cm}$ and $23 \mathrm{~cm}$ height, with a capacity of 3.51 , and eight drainage holes at the bottom. The chosen pot volume and height represented the rooting space of carrots grown on dams in the field. The moisture content of the soil was determined by oven-drying $\left(105^{\circ} \mathrm{C}\right)$ three samples of $3700 \mathrm{~g}$ for $24 \mathrm{~h}$. An average moisture content of $10.4 \%$ was measured and $2.9 \mathrm{~kg}$ of steamsterilized soil was then filled into the pots and gently compressed using a wooden stamp. Soil moisture was then adjusted to $17 \%$ before nematode inoculation.

\section{Nematode density preparation and inoculation}

The volume of the stock suspension of nematodes was adjusted to the highest density required, after which a dilution series was made according to a $\log$ series of $2^{x}$ where $x$ is an integer ranging from -3 to 7 . To distribute the nematodes more or less uniformly through the soil column of the pot, a $29.7 \mathrm{~cm}$ closed bottom needle with side holes was used. Each needle was inserted into the soil down to $2.5 \mathrm{~cm}$ above the bottom of the pot and the inoculum was released while gently withdrawing the needle. Controls were inoculated with water. Nine, $3 \mathrm{ml}$ injections pot $^{-1}$, totalling $27 \mathrm{ml}$, were used to apply the required number of nematodes to each pot, obtaining a series of densities ranging from 0.125 to 128 P. penetrans (g dry soil) ${ }^{-1}$.

Glasshouse conditions and planting

Daily temperature of the glasshouse was maintained at $23{ }^{\circ} \mathrm{C}$ and $16 \mathrm{~h}$ of day light provided using $600 \mathrm{~W}$,
58,500 lumen lamps (Norka-Lighting ${ }^{\circledR}$, Hamburg, Germany). In order to synchronise the germination of the carrot seeds with the inoculation of the nematodes into the soil, seeds were soaked in water for 4 days prior to planting. The detailed procedure is described in Heve et al. (2015). After inoculation, each pot was sown with either 2,4 or 18 seeds pot $^{-1}$ to obtain an equivalent seed density of 1, 2 and 10 million ha ${ }^{-1}$, respectively, which complies with normal practice. Carrot seeds were planted at $5 \mathrm{~mm}$ depth. To make sure that the required numbers of plants per pot of 2, 4 and 18 seeds were obtained, 2, 4 and 4 extra seeds per seed density were added, respectively, based on a $94 \%$ germination rate reported by Heve et al. (2015) for cv. Nerac. Extra seedlings were thinned immediately after germination by removing the aboveground part. Each nematode and seed density combination was replicated five times. In total, 180 pots were used for this experiment.

\section{Watering and fertilizing}

To minimize evaporation and avoid splashing during watering, each pot was covered with perforated black polythene-sheet. Throughout the growing period, pots were weighed and watered weekly to restore the soil moisture content to $17 \%$. In between, five randomly selected pots were weighed and a fixed volume of water was given to each pot, if necessary. The pots were arranged in a complete randomised design on raised benches in a glasshouse and during watering pots were rotated to minimize positional effects. Moreover, the increase in weight due to plant growth was taken into consideration during watering ( $1 \mathrm{ml}$ extra water for each $\mathrm{g}$ of growth based on prior studies for cv. Nerac (Heve et al. 2015). Plants were fertilized weekly with $0.3 \%$ WUXAL ${ }^{\circledR}$ Super liquid foliar fertilizer (Agrarverstand Oberland, Schongau, Germany). On account of the growth pattern described in Heve et al. (2015), carrots were harvested 83 days after germination when they reached the industry desired diameter of the carrot taproot.

\section{Observations and measurements}

Seed germination date of carrots was recorded. At harvest, fresh and dry shoot, root and taproot weights were measured for each plant. Dry weights were measured after $24 \mathrm{~h}$ oven drying at $105{ }^{\circ} \mathrm{C}$. The diameter and length of each carrot was measured using an electronic 
Vernier-calliper. The commercial or industrial market quality of the carrot taproots was visually graded with a score of either 0 (absent) or 1 (present) for several quality features, which include carrot taproots being forked or branched, hairy-, stubby, misshapen or rotten. Carrot taproots with growth cracks, pale green coloured heads $(>1 \mathrm{~cm})$ and taproot head diameter outside a range of 12-25 mm (all not nematode related) were also rejected according to industrial standards. Carrot taproots were considered as acceptable when all negative quality features were absent.

Estimation of final population densities at harvest

Nematode densities from the organic fraction of each pot were determined from the entire root system and from the first $0.5 \mathrm{~mm}$ peel of all carrot taproots, independent of their industrial quality. The roots of each pot were removed from the soil by hand; the soil was then sieved gently through a 3 $\mathrm{mm}$ mesh sieve to collect the root hairs. Roots were rinsed with water to remove any adhering soil and then cut into pieces of $1 \mathrm{~cm}$. With a multi-functional carrot peeler with twin swivelling blades (BONET) the carrot peel was collected, cut in pieces of $1 \mathrm{~cm}^{2}$ and added to the roots (http://bonet.en.alibaba.com/). Both were placed in a $9 \mathrm{~cm}$ diam. extraction sieve $(150 \mu \mathrm{m})$ on top of an extraction dish of $12 \mathrm{~cm}$ diam. and placed in a Seinhorst mist-chamber (Seinhorst 1988). In the mist-chamber the sieves were exposed to a $45 \mathrm{~min}$ cycle providing a fine mist of $20{ }^{\circ} \mathrm{C}$ during $15 \mathrm{~min}$ and a rest period of $30 \mathrm{~min}$. Hatched nematodes were tapped every week for 28 days.

Nematodes from the mineral fraction (the soil) were extracted from aliquots of $250 \mathrm{ml}$ soil using the centrifugal flotation $\left(\mathrm{MgSO}_{4}\right)$ method (Hooper et al. 2005). The nematodes from both fractions were collected into glass bottles and stored in a refrigerator at $4{ }^{\circ} \mathrm{C}$ until counted. The final nematode population density $(P f)$, combined number of adults and juveniles was then estimated by adding the nematode densities of both fractions ( $\mathrm{g}$ dry soil $)^{-1}$.

\section{Statistical analysis and modelling}

All data sets were analysed using scripts written in Tinn-R, version 3.0.3.6 and run in R-version 3.0.1 using non-linear regression (Dalgaard 2002). The goodness of fit of models was expressed as the coefficient of determination $\left(R^{2}\right)$, adjusted to degrees of freedom. The Least significant difference (LSD) at $p=0.05$ was calculated for all estimated parameters between seed density if necessary.

\section{Diameter, length, yield and quality of carrot taproots}

Seinhorst's Eq. (1) as described by Schomaker and Been (2013) was fitted to the data of carrot length, -diameter, relative yield (weight of all carrot taproots), and quality yield (weight of all acceptable carrot taproots), based on the standards acceptable for the industry. Before fitting the model to the data, each measurement was averaged over the replicates for each nematode density.

$$
\begin{array}{ll}
y=m+(1-m) 0.95^{P i / T-1} & \text { for } P i>T \\
y \quad 1 \quad 1 & \text { for } P i \leq T
\end{array}
$$

The parameters tolerance limits $(T)$ and relative minimum yield $(m)$ were estimated for all measurements.

\section{Population dynamics}

The $P f$ obtained from each density was first log transformed and then averaged over replications and back transformed. The relation between $P i$ and $P f$ was modelled to estimate the maximum multiplication rate $(a)$ and the maximum population density $(M)$ for each seed density, using Eq. (2) for migratory nematodes with more than one generation per growing period (Seinhorst 1966; Teklu et al. 2014).

$$
P f=M^{*} P i /(P i+M / a)
$$

\section{Results}

\section{Carrot establishment}

Almost all seedlings at 2 and 4 seeds pot $^{-1}$, at all population densities, developed into carrot plants. Only at 18 seeds pot ${ }^{-1}$ a negative correlation between $P i$ and plant establishment became noticeable. Carrot plants without carrot taproots occurred only at the highest density of 128 P. penetrans (g dry soil) ${ }^{-1}$ at all seed densities. No correlation between taproot presence and $P i$ could be established, except for 18 seeds pot ${ }^{-1}$ (Fig. 1). A few averages lie slightly above the intended 
Fig. 1 The relation between the initial population density $(P i)$ of $P$. penetrans, plotted on a $\log$ scale, and the number of carrot taproots harvested at 2, 4 and 18 seeds $\operatorname{pot}^{-1}$

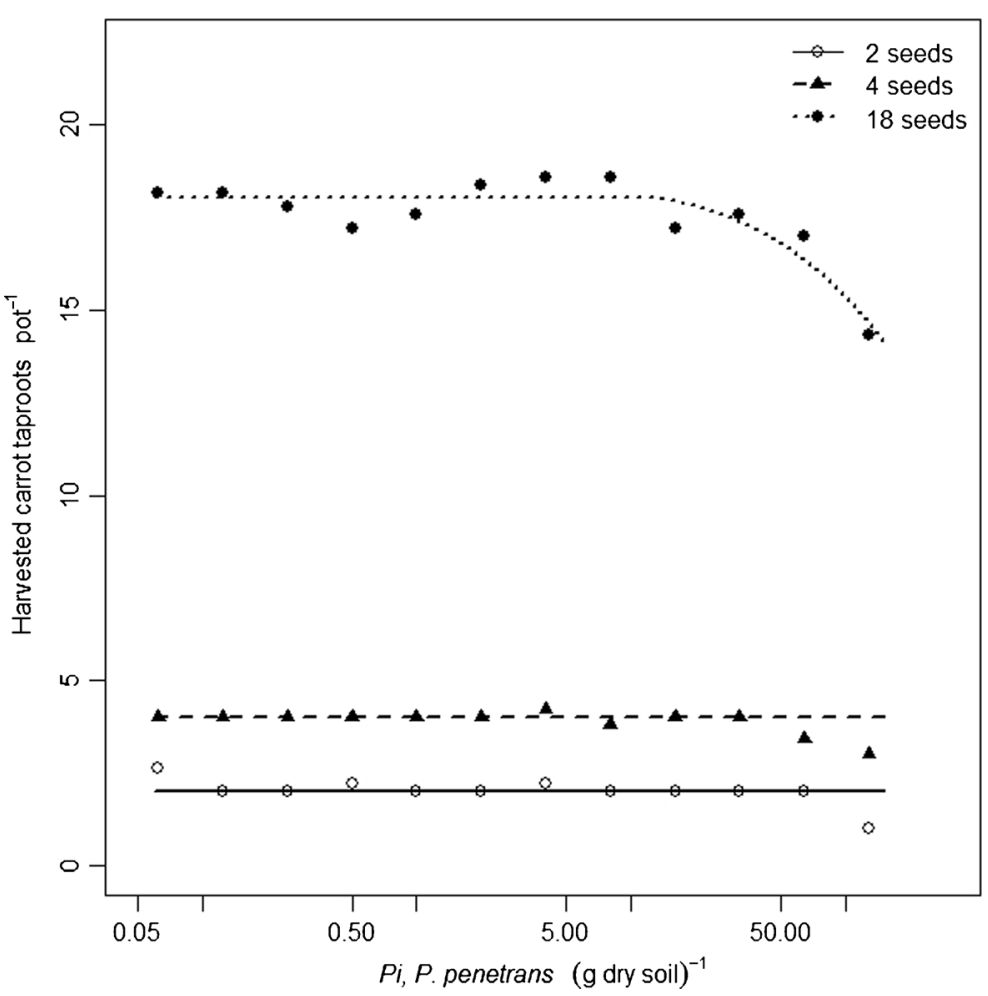

seed density of the pot which probably resulted from surplus seedlings that escaped the thinning.

\section{Carrot taproot growth}

Carrot taproots at all seed densities attained a diameter of $12-25 \mathrm{~mm}$, which is required for the canning industry, 83 days after sowing. Both carrot taproot diameter and, especially, carrot taproot length were negatively correlated with increasing $P i$. No differences were detected for the tolerance limits $\left(T_{\mathrm{d}}\right)$ of $0.79,2.71$, and 0.23 P. penetrans (g dry soil) $)^{-1}$ and the relative minimum diameter $\left(m_{\mathrm{d}}\right)$ of $0.90,0.83$, and 0.95 at 2,4 , and 18 seeds pot $^{-1}$, respectively. The tolerance limits $\left(T_{\mathrm{L}}\right)$ for length were 1.33, 1.55, and 1.21 P. penetrans (g dry soil) ${ }^{-1}$ for 2,4 , and 18 seeds $\operatorname{pot}^{-1}$, respectively. No statistical difference was found. The relative minimum length $\left(m_{\mathrm{L}}\right)$ was $0.47,0.48$, and 0.76 at 2,4 , and 18 seeds $\operatorname{pot}^{-1}$, respectively. The $m_{\mathrm{L}}$ value at 18 seeds $\operatorname{pot}^{-1}$ was significantly higher than those at 2 and 4 seeds pot $^{-1}$. Both maximum diameter and length of carrot taproots were inversely related to seed density. Parameter values are summarized in Table 1.
Taproot yield

Equation 1 was fitted to the data of carrot taproot yield to investigate the relation between $P i$ and yield for each seed density (Fig. 2). Carrot taproot yield started to be affected at $P i$ values larger than $\left(T_{\mathrm{y}}\right)$ of 1.51, 1.88, and 1.37 P. penetrans (g dry soil) ${ }^{-1}$ at respective seed densities. Minimum yields $\left(m_{\mathrm{y}}\right)$ of $0.20,0.29$, and 0.60 at 2,4 , and 18 seeds pot ${ }^{-1}$ were estimated, respectively. No significant difference in $T_{\mathrm{y}}$ value could be established between the seed densities. However, the $m_{\mathrm{y}}$ value at 18 seeds $\operatorname{pot}^{-1}$ was significantly higher than that of 2 and 4 seeds pot $^{-1}$. Generally, taproot weight increased with increasing seed densities. Maximum carrot taproot weight $Y_{\max (\mathrm{y})}$, of 59.90, 76.14, and $100.32 \mathrm{~g}$ were measured at 2, 4, and 18 seeds pot ${ }^{-1}$, respectively. Estimated model parameter values for carrot taproot yield and LSD are listed in Table 1.

\section{Taproots quality}

The relation between $P i$ and quality yield is displayed in Fig. $3 \mathrm{a}$ and a summary of parameter values is provided in Table 1. Tolerance limits $\left(T_{\mathrm{q}}\right)$ of $0.67,0.18$, and 0.40 
Table 1 Parameter values for Seinhorst Eq. (1) for the relation between initial population density $(P i)$ of $P$. penetrans and measured variables of carrots. $P i$ and $T$ are expressed in P. penetrans $(\mathrm{g}$ dry soil) $)^{-1}$ while, $y$ and $m$ are proportions and $Y_{\max }$ is expressed in grams. Comparison of the parameter values at 2 seeds $\operatorname{pot}^{-1}$ was done with that of 4 and 18 seeds pot $^{-1}$

Parameter values; diameter of carrot taproots

According to the equation: $y_{\mathrm{d}}=m_{\mathrm{d}}+\left(1-m_{\mathrm{d}}\right) 0.95^{P i / T}{ }_{\mathrm{d}}^{-1}$ for $P i>T_{\mathrm{d}}$ and $y_{\mathrm{d}}=1$ for $P i \leq T_{\mathrm{d}}$

$\begin{array}{lllllllllll}\text { Seed density } & T_{\mathrm{d}} & m_{\mathrm{d}} & Y_{\max (\mathrm{d})} & \mathrm{SE}_{T(\mathrm{~d})} & \mathrm{SE}_{m(\mathrm{~d})} & \mathrm{SE}_{Y \max (\mathrm{d})} & R^{2} & \mathrm{df} & \mathrm{LSD}_{T(\mathrm{~d})} & \mathrm{LSD}_{m(\mathrm{~d})} \\ 2 & 0.79 & 0.90 & 22.65 & 1.09 & 0.04 & 0.40 & 0.52 & 8 & - & - \\ 4 & 2.71 & 0.83 & 20.39 & 2.82 & 0.11 & 0.22 & 0.71 & 8 & 6.41 & 0.26 \\ 18 & 0.23 & 0.95 & 14.96 & 0.11 & 0.01 & 0.10 & 0.79 & 8 & 2.32 & 0.10\end{array}$

Parameter values; length of the carrot taproots

According to the equation: $y_{\mathrm{L}}=m_{\mathrm{L}}+\left(1-m_{\mathrm{L}}\right) 0.95_{\mathrm{L}}^{P i / T}{ }^{-1}$ for $P i>T_{\mathrm{L}}$ and $y_{\mathrm{L}}=1$ for $P i \leq T_{\mathrm{L}}$

$\begin{array}{lllllllllll}\text { Seed density } & T_{\mathrm{L}} & m_{\mathrm{L}} & Y_{\max (\mathrm{L})} & \mathrm{SE}_{T(\mathrm{~L})} & \mathrm{SE}_{m(\mathrm{~L})} & \mathrm{SE}_{Y \max (\mathrm{L})} & R^{2} & \mathrm{df} & \mathrm{LSD}_{T(\mathrm{~L})} \mathrm{LSD}_{m(\mathrm{~L})} \\ 2 & 1.33 & 0.47 & 120.50 & 1.09 & 0.13 & 6.00 & 0.82 & 9 & - & - \\ 4 & 1.55 & 0.48 & 101.64 & 1.18 & 0.12 & 4.35 & 0.85 & 9 & 3.37 & 0.38 \\ 18 & 1.21 & 0.76 & 54.74 & 0.35 & 0.02 & 0.62 & 0.94 & 9 & 2.41 & * 0.27\end{array}$

Parameter values; carrot taproot yield

According to the equation: $y=m_{\mathrm{y}}+\left(1-m_{\mathrm{y}}\right) 0.95^{P i / T}{ }_{\mathrm{y}}^{-1}$ for $P i>T_{\mathrm{y}}$ and $y=1$ for $P i \leq T_{\mathrm{y}}$

$\begin{array}{lllllllllll}\text { Seed density } & T_{\mathrm{y}} & m_{\mathrm{y}} & Y_{\max (\mathrm{y})} & \mathrm{SE}_{T(\mathrm{y})} & \mathrm{SE}_{m}(\mathrm{y}) & \mathrm{SE}_{Y \max (\mathrm{y})} & R^{2} & \mathrm{df} & \operatorname{LSD}_{T(\mathrm{y})} \mathrm{LSD}_{m}(\mathrm{y}) \\ 2 & 1.51 & 0.20 & 59.90 & 0.71 & 0.13 & 2.78 & 0.91 & 9 & - & - \\ 4 & 1.88 & 0.29 & 76.14 & 0.44 & 0.07 & 1.65 & 0.97 & 9 & 1.75 & 0.30 \\ 18 & 1.37 & 0.60 & 100.32 & 0.91 & 0.08 & 3.16 & 0.86 & 9 & 2.42\end{array}$

Parameter values; carrot taproot quality yield

According to the equation: $y_{\mathrm{q}}=m_{\mathrm{q}}+\left(1-m_{\mathrm{q}}\right) 0.95^{P i / T}{ }_{\mathrm{q}}^{-1}$ for $P i>T_{\mathrm{q}}$ and $y_{\mathrm{q}}=1$ for $P i \leq T_{\mathrm{q}}$

\begin{tabular}{lllllllllll} 
Seed density & $T_{\mathrm{q}}$ & $m_{\mathrm{q}}$ & $Y_{\max (\mathrm{q})}$ & $\mathrm{SE}_{T(\mathrm{~m})}$ & $\mathrm{SE}_{m(\mathrm{q})}$ & $\mathrm{SE}_{Y \max (\mathrm{q})}$ & $R^{2}$ & $\mathrm{df}$ & $\mathrm{LSD}_{T(\mathrm{~d})}$ & $\mathrm{LSD}_{m(\mathrm{q})}$ \\
2 & 0.67 & 0.05 & 43.39 & 0.26 & 0.13 & 3.64 & 0.85 & 9 & - & - \\
4 & 0.18 & 0.07 & 70.06 & 0.09 & 0.08 & 6.15 & 0.92 & 9 & 0.58 & 0.32 \\
18 & 0.40 & 0.20 & 91.25 & 0.13 & 0.07 & 5.01 & 0.93 & 9 & 0.62 & 0.31 \\
\hline
\end{tabular}

*Significantly different at $p=0.05$

P. penetrans (g dry soil) ${ }^{-1}$ at 2,4 , and 18 seeds pot $^{-1}$ were estimated, respectively. The minimum quality yields $\left(m_{\mathrm{q}}\right)$ were $0.05,0.07$, and 0.20 at 2,4 , and 18 seeds pot $^{-1}$, respectively. No statistical significant difference could be recognized for the parameters $T_{\mathrm{q}}$ and $m_{\mathrm{q}}$ between seed densities. Maximum quality yields $Y_{\max (\mathrm{q})}$, of 40.39, 70.06, and $91.25 \mathrm{~g}$ were measured at 2, 4, and 18 seeds pot ${ }^{-1}$, respectively. As $Y_{\max (\mathrm{q})}$ is seed density dependent, the same data are plotted relatively for a better comparison in Fig. 3 b.

Quality losses, associated with $P$. penetrans, included forked, misshapen, constricted, rotted and hairy carrots. Non-nematode related quality damage, like greening of the hypocotyl caused by exposure to sunlight, was also noticed. However, a major part of the quality losses could be attributed to forked and misshapen carrot taproots; both symptoms were positively correlated with $P i$. Only a small number of carrot taproots suffering from rot were observed, mainly at 2 and 4 seed pot $^{-1}$. This quality problem was $P i$ independent. Little quality loss was also observed at $P i=0$.

Population dynamics

The model for population dynamics (Eq. 2) fitted well to the relation between $P i$ and $P f$. All the fitted lines are above the equilibrium density line $(P f=P i)$. The relation between $P i$ and $P f$ at all seed densities according to Eq. (2) is shown in Fig. 4. Maximum multiplication rates $(a)$ of $19.58,9.99$, and 17.54 and maximum population densities $(M)$ of 49.86, 43.21, and 60.37 P. penetrans (g dry soil) ${ }^{-1}$ at 2,4 , and 18 seeds pot ${ }^{-1}$ were estimated, respectively. Both values for $a$ and $M$ at 2 and 18 seeds pot $^{-1}$ were significantly higher than those at 4 seeds pot $^{-1}$ (Table 2). 
Fig. 2 The relation between the initial population density, $(P i)$ of $P$. penetrans, on a log scale, and relative carrot taproot yield at 2,4 and 18 seeds pot $^{-1}$. Fitted line according to the Seinhorst yield loss equation: $y=m_{\mathrm{y}}+\left(1-m_{\mathrm{y}}\right)$ $0.95^{P i / T}{ }^{-1}$ for $P i>T_{\mathrm{y}}$ and $y=1$ for $P i \leq T_{\mathrm{y}}$

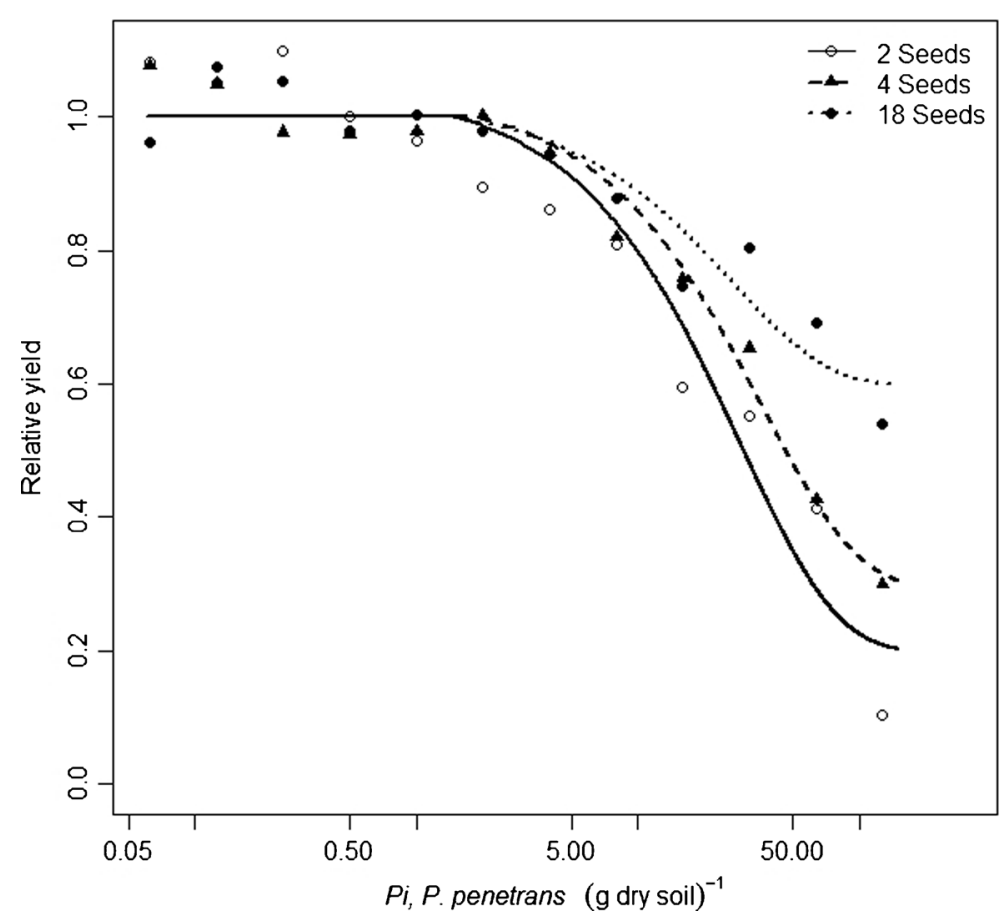

\section{Discussion}

Establishment and growth

Establishment of seeds into carrot plant was independent of the $P i$, except at 18 seeds pot ${ }^{-1}$. This might indicate that at the highest seed density a combined effect of competition between seedlings and attack by high nematode densities occurred. The additional reduction of taproot development by carrot plants only occurred at the highest Pi of 128 P. penetrans (g dry soil) ${ }^{-1}$ at all seed densities. A more pronounced correlation might be obtained when even higher nematode densities would be added to the $P i$ series. However, these densities would be surpassing the $P i$ encountered in the field in spring, which are seldom higher than $50 \mathrm{P}$. penetrans (g dry soil) ${ }^{-1}$ or ca. 5000 P. penetrans $(100 \mathrm{ml} \text { soil })^{-1}$ in The Netherlands (L.P.G. Molendijk, pers.com.). Therefore, little practical value is to be expected in exploring higher $P i$ on the establishment of carrots. Establishment of cv. Nerac into carrot plant was reported to be independent of seed density and $P i$ of $M$. chitwoodi, but carrot plants that developed carrot taproots were negatively correlated with $P i$ at the same seed densities (Heve et al. 2015).

The negative correlation between carrot taproot length and diameter with the $P i$, confirms previous results from Coosemans (1975) and Vrain and Belair (1981). Also, both taproot diameter and length were
Fig. 3 The relation between the initial population density $(\mathrm{Pi})$ of $P$. penetrans, on a log scale and a: Carrot taproot quality yield ( $\mathrm{g}$ ) and $\mathbf{b}$ : Relative carrot taproot quality yield at 2,4 , and 18 seeds $\operatorname{pot}^{-1}$. Fitted lines according to the Seinhorst yield loss equation: $y_{\mathrm{q}}=m_{\mathrm{q}}+\left(1-m_{\mathrm{q}}\right) 0.95^{P i / T}{ }^{-1}$ for $P i>T_{\mathrm{q}}$ and $y_{\mathrm{q}}=1$ for $P i \leq T_{\mathrm{q}}$

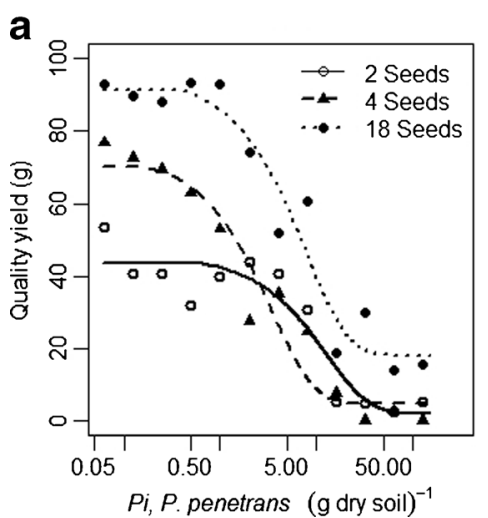


Fig. 4 The relation between initial $(P i)$ and final $(P f)$ population densities of $P$. penetrans, on a log scale at 2,4 and 18 seeds pot $^{-1}$. Fitted lines according to the equation: $P f=M^{*} P i /(P i+M / a)$ for population dynamics (Seinhorst 1966). Straight diagonal dashed line: population equilibrium line: $P f=P i$

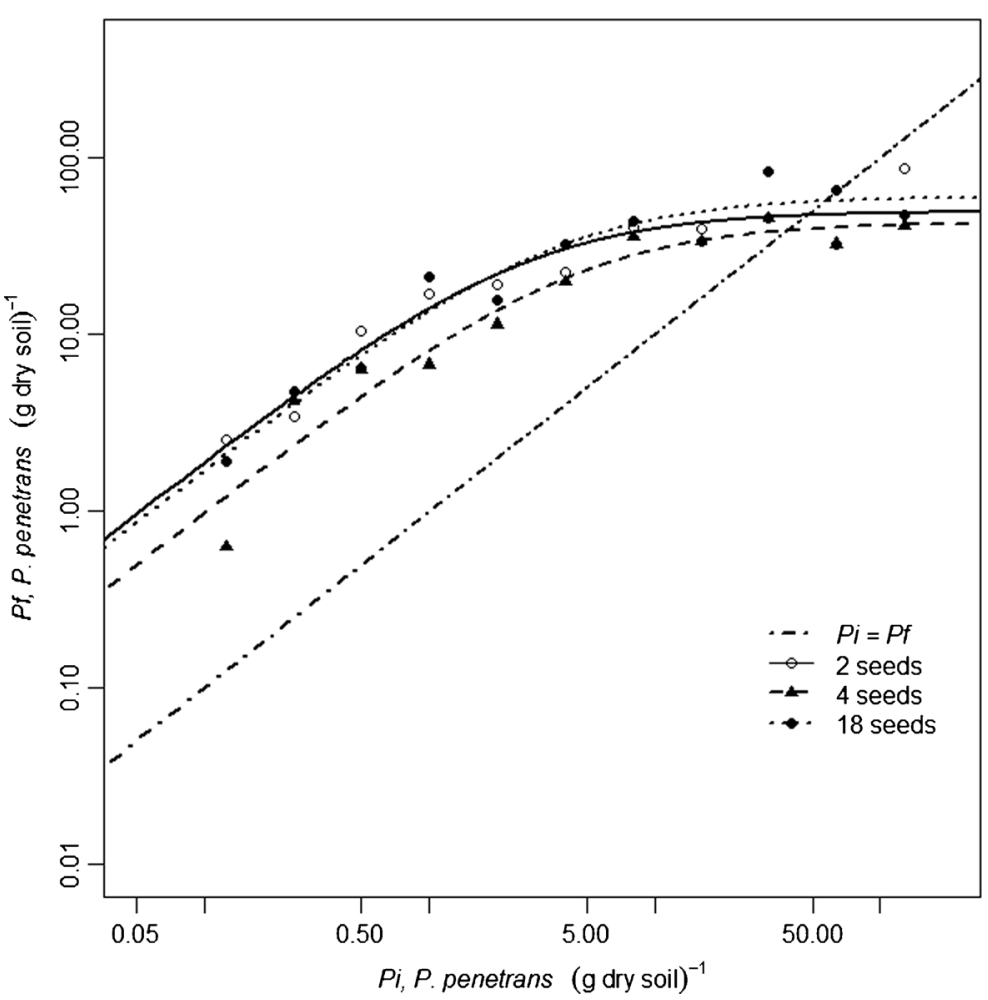

negatively correlated with increasing seed density, which reflects the purpose of varying seed densities to provide for different carrot taproot sizes required by the canning industry. These results comply with those of Heve et al. (2015) at identical seeding rates of cv. Nerac exposed to M. chitwoodi.

Yield and quality loss

The tolerance limits for carrot yield $\left(T_{\mathrm{y}}\right)$ were not affected by increasing seed densities in this experiment.

Table 2 Parameter values of the population dynamics model for the relation between initial $(P i)$ and final population density $(P f)$ both measured as $P$. penetrans (g dry soil) ${ }^{-1}$ at 2,4 and 18 seeds $\operatorname{pot}^{-1}$. The model for migratory nematodes with more than one generation: $P f=M * P i /(P i+M / a)$ was used. Multiplication
Similar threshold levels for yield loss of carrot were reported by Oostenbrink (1972), Seinhorst (1998) and Pudasaini (2006) with $T_{\mathrm{y}}$ values of $0.3-1.8,1.4$, and 1.03 P. penetrans ( $\mathrm{g}$ dry soil) ${ }^{-1}$, respectively. A $T_{\mathrm{y}}$ value of ca. 0.5 P. crenatus (g soil) ${ }^{-1}$, was reported for other species of Pratylenchus by Weischer and Brown (2000). Seinhorst (1998) and Pudasaini (2006) reported $m_{\mathrm{y}}$ values for carrots of 0.49 and 0.36 , respectively, which do not deviate from the range found in this experiment. Values of $0.76-0.78$ for $m_{\mathrm{y}}$ of $P$. crenatus on Kurodatype carrot were reported by Hay and Pethybridge

rate $(a)$ is dimensionless while, maximum population $(M)$ is measured as $P$. penetrans (g dry soil) ${ }^{-1}$. Comparison of the parameter values of 2 seeds pot $^{-1}$ was done with that of 4 and 18 seeds pot $^{-1}$

Parameter values (Population dynamics)

\begin{tabular}{|c|c|c|c|c|c|c|c|c|}
\hline Seed density & $a$ & $M$ & $\mathrm{SE}_{a}$ & $\mathrm{SE}_{M}$ & $R^{2}$ & $\mathrm{df}$ & $\operatorname{LSD}_{(a)}$ & $\operatorname{LSD}_{(M)}$ \\
\hline 2 & 19.58 & 49.86 & 3.33 & 7.26 & 0.93 & 9 & - & - \\
\hline 4 & 9.99 & 43.21 & 1.79 & 7.95 & 0.93 & 9 & $* 0.52$ & $* 0.49$ \\
\hline 18 & 17.54 & 60.37 & 2.79 & 9.14 & 0.94 & 9 & $* 0.49$ & $* 0.44$ \\
\hline
\end{tabular}

*Significantly different at $p=0.05$ 
(2005). In that case, differences of host suitability within species and carrot cultivars can be expected. With increasing seed density a higher total marketable carrot taproot was obtained and, more important, an increasing minimum yield $\left(m_{\mathrm{y}}\right)$, similar to observations by Heve et al. (2015) with M. chitwoodi. This indicates the distribution of the initial population density over a larger root volume per unit soil, when the seed density is increased.

The tolerance limits for quality yield varied between seed densities, but were not statistically significant. Coosemans (1975) reported about $75 \%$ of the carrots being forked at 10 P. penetrans $(100 \mathrm{ml} \mathrm{soil})^{-1}$ which is equivalent to $c a .0 .08$ P. penetrans ( $\mathrm{g}$ soil) $)^{-1}$, a density even lower than the $T_{\mathrm{q}}$ in this experiment. Sato et al. (2009) reports a $T_{\mathrm{q}}$ value of 0.11 P. penetrans (g soil) ${ }^{-1}$ for radish. Different to P. penetrans, Heve et al. (2015) observed increasing $T_{\mathrm{q}}$ values with an increasing seed density for M. chitwoodi on the same carrot cultivar. In general, results confirm that quality loss by $P$. penetrans was more severe than yield loss; both for the parameters $T$ and $m$ as was also reported by Coosemans (1975) and for M. chitwoodi on carrot (Heve et al. 2015) and potato (Norshie et al. 2011).

\section{Population dynamics and management}

The relatively higher $a$ and $M$ values at 2 seeds $\operatorname{pot}^{-1}$ compared to those at 4 seeds pot ${ }^{-1}$ and, for $a$, even at 18 seeds pot $^{-1}$ is difficult to elucidate. A possible explanation could be a large variation in the nematode density estimation of $P$. penetrans. Both experience and literature indicate that $50 \%$ of the population of $P$. penetrans is retrieved from the fine root hairs; a fraction which can easily be lost when retrieving the roots from the soil is handled too rough (Pudasaini et al. 2006a). However, extreme care was taken, soil was sieved two to three times to ensure retrieval of the fine roots and any variation would not have been limited to a single seed density. Pudasaini (2006) reported a multiplication rate $(a=5.9)$ and maximum population density, $M=37.3$ P. penetrans ( $\mathrm{g}$ dry soil) $)^{-1}$ ) on carrots, respectively, which is more or less similar to what was found at 2 and 4 seeds pot $^{-1}$ in this study, despite some differences in methodology applied. Heve et al. (2015) observed increasing $a$ and $M$ values for $M$. chitwoodi with increasing seed density as a result of an increasing root volume per unit soil and, consequently, more space for the nematode to feed.
P. penetrans multiplied well, indicating that cv. Nerac is a good host, unlike M. chitwoodi (Heve et al. 2015). This implies, population densities after harvest will be increased and management might be required before the next crop is grown. The use of Tagetes patula (marigold) is commercially applied in The Netherlands and proved to be even more effective than soil fumigation to control $P$. penetrans (Evenhuis et al. 2004). Currently, Tagetes is grown on 5000 to 6000 ha arable land, mainly aimed to control this nematode in strawberry, flower bulbs, roses, apple orchards, and vegetables (L.P.G. Molendijk, pers.com.). When five crop rotations were compared, population densities of P. penetrans were lowest after cropping Tagetes patula compared to barley, timothy, annual ryegrass and pearl millet (Kimpinski and Sanderson 2004). According to Pudasaini et al. (2006b), using better sampling methodology than Kimpinski and Sanderson (2004), Tagetes patula reduced population densities by more than $90 \%$ in Belgium field trials. An additional $64 \%$ natural population decline in the following fallow period after Tagetes patula had been grown and strict weed control was applied (Pudasaini et al. 2006b). The combined use of non-hosts (Tagetes patula) and poor hosts (perennial rye-grass, Avena strigosa, ) and winter fallow provides the possibility to decrease population densities and thus increase both carrot yield and quality. As chemical control becomes more difficult as a result of legislation, there is a need to establish the host status of more crops, or even obtain resistant crops, which could be used in rotations with carrots to manage $P$. penetrans.

\section{Conclusion}

A correlation between $P i$ of $P$. penetrans, yield, quality and $P f$ was demonstrated for each seed density tested in this experiment. This indicates the possibility to predict yield losses and population development based on preplant population densities of $P$. penetrans and, therefore, to manage this nematode using an integrated pest management strategy. The average quality threshold level $T_{\mathrm{q}}$ of 0.4 P. penetrans (g dry soil) ${ }^{-1}$ in this experiment equates to about $50 P$. penetrans $(100 \mathrm{ml})^{-1}$ and deviates little from the currently used standard in Germany and the Netherlands. Hardly any quality yield loss will be suffered at a $P i$ of $0.8 P$. penetrans (g dry soil) ${ }^{-1}$ or $c a$. 100 P. penetrans $(100 \mathrm{ml} \text { soil })^{-1}$. At relatively higher $P i$ the possibility of cropping at 10 million seeds $\mathrm{ha}^{-1}$ can 
be considered, which should provide higher quality yields compared to lower seed densities. Actually, higher quality losses up to $25 \%$ of the carrots produced are accepted by the canning industry, e.g. in The Netherlands when fields with favourable low infestations are scarce.

As tolerance limit generally does not deviate between pot and field experiments and is not related to host status the threshold values reported can be considered to be applicable for practical use. Contrary, the minimum yield is much more variable and varies from field to field and year to year due to weather and field conditions. Therefore, validation in the field is needed to ascertain the variation of the minimum yield and quality loss $\left(m_{\mathrm{y}}\right.$ and $\left.m_{\mathrm{q}}\right)$ to be encountered. Parallel to this, field tests have to be carried out to parameterize the model of nematode population dynamics as, generally, under glasshouse conditions, due to the completely optimized growing conditions for the host and, therefore, for the tested plant-parasitic nematode, these are higher than under field conditions. This would also provide information concerning future translation of glasshouse data to the field, as has been done for Globodera pallida and potato (Been et al. 1994).

Acknowledgments The authors would like to acknowledge the EU for funding this research through the ProGemüse project (INTERREG IV-A II-3-04-100). Special thanks to Corrie H. Schomaker for the modelling and statistical analysis. J.E. Beniers, Falko Lange, Mechthild Neuhaus, Agnes Windt, Dorothee Suttorp, W.K. Heve, Ulrike Hakl, Claudia Ergezinger, Sabine Schöbel, Andrea Nicot and Monika Breuch are thanked for their unreserved technical support.

Open Access This article is distributed under the terms of the Creative Commons Attribution 4.0 International License (http://creativecommons.org/licenses/by/4.0/), which permits unrestricted use, distribution, and reproduction in any medium, provided you give appropriate credit to the original author(s) and the source, provide a link to the Creative Commons license, and indicate if changes were made.

\section{References}

Barker, K. R., \& Olthof, T. H. A. (1976). Relationships between nematode population densities and crop responses. Annual Review of Phytopathology, 14, 327-353.

Been, T. H., Schomaker, C. H., \& Seinhorst, J. W. (1994). An advisory system for the management of potato cyst nematodes (Globodera spp.). In A. J. Haverkort \& D. K. L. McKerron (Eds.), Ecology and modelling of potato crops under conditions limiting growth (pp. 305-321). Dordrecht: Kluwer Academic Publishers.

Castillo, P. \& Volvas, N. (2007). Pratylenchus (Nematoda: Pratylenchidae); Diagnosis, biology, pathogenicity and management. Nematology Monographs and Perspectives 6. Leiden, The Netherlands, Brill, 529 pp.

Coosemans, J. (1975). The influence of Pratylenchus penetrans on growth of Impatiens balsamina L., Daucus carota L., Linen usitatissimum L., and Chrysanthemum indicum L. Mededelingen van de Faculteit Landbouwwetenschappen: Gent University, 40, 465-471.

Dalgaard, P. (2002). Introductory statistics with R. New York: Springer. $267 \mathrm{pp}$.

Evenhuis, A., Korthals, G. W., \& Molendijk, L. P. G. (2004). Tagetes patula as an effective catch crop for long-term control of Pratylenchus penetrans. Nematology, 6, 877-881.

Ferris, H. (1978). Nematode economic thresholds: derivation, requirements, and theoretical considerations. Journal of Nematology, 10, 341-350.

Gugino, B. K., Abawi, G. S., \& Ludwig, J. W. (2006). Damage and management of Meloidogyne hapla using oxamyl on carrot in New York. Journal of Nematology, 38, 483-490.

Hahn, S. (1958). Wurzelgallenälchen (Meloidogyne hapla Chitwood) als Freilandschädlinge an Salat und Möhren. Nachrichtenblatt Dtsch Pflanzenschutzdienst Braunschweig, 10, 123-126.

Hallmann, J., Frankenberg, A., Paffrath, A., \& Schmidt, H. (2007). Occurrence and importance of plant-parasitic nematodes in organic farming in Germany. Nematology, 9, 869-879.

Hay, F. S., \& Pethybridge, S. J. (2005). Nematodes associated with carrot production in Tasmania, Australia, and the effect of Pratylenchus crenatus on yield and quality of Kuroda-type carrot. Plant Disease, 89, 1175-1180.

Heve, W. K., Been, T. H., Schomaker, C. H., \& Teklu, M. G. (2015). Damage thresholds and population dynamics of Meloidogyne chitwoodi on carrot (Daucus carota L., cv. Nerac) at different seed densities. Nematology, 17, 501-514.

Hooper, D. J., Hallmann, J., Subbotin, S., \& Luc, M. (2005). Methods for extracting and detection of plant and soil nematodes. In R. A. Sikora \& J. Bridge (Eds.), Plant parasitic nematodes in subtropical and tropical agriculture (2nd ed., pp. 53-86). Wallingford: CABI Publishing.

Jones, J., Haegeman, A., Danchin, E. G. J., Gaur, H. S., Helder, J., Jones, M. G. K., Kikuchi, T., Manzanilla- López, R., Palomares-Rius, J., Wesemael, W. M. L., \& Perry, R. N. (2013). Top 10 plant-parasitic nematodes in molecular plant pathology. Molecular Plant Pathology, 14, 946-961.

Kimpinski, J., \& Sanderson, K. (2004). Effects of crop rotations on carrot yield and on the nematodes Pratylenchus penetrans and Meloidogyne hapla. Phytoprotection, 85, 13-17.

Noling, J. W. (2012). Nematode management in carrots. ENY-021 Florida Cooperative Extension Service. http://edis.ifas.ufl. edu/.

Norshie, P. M., Been, T. H., \& Schomaker, C. H. (2011). Estimation of partial resistance in potato genotypes against Meloidogyne chitwoodi. Nematology, 13, 477-489.

Oostenbrink, M. (1972). Evaluation and integration of nematode control methods. In J. M. Webster (Ed.), Economic nematology (pp. 497-514). San Diego: Academic Press.

Potter, J. W., \& Olthof, T. H. A. (1993). Nematode pests of vegetable crops. In K. Evans, D. L. Trudgill, \& J. M. 
Webster (Eds.), Plant parasitic nematodes in temperate agriculture (pp. 171-207). Wallingford: CAB International.

Pudasaini, M. P. (2006). Interaction between the root lesion nematode, Pratylenchus penetrans, and field crops. $\mathrm{PhD}$ thesis, Ghent University, Ghent, Belgium.

Pudasaini, M. P., Schomaker, C. H., Been, T. H., \& Moens, M. (2006a). Vertical distribution of the plant-parasitic nematode, Pratylenchus penetrans, under four field crops. Phytopathology, 96, 226-233.

Pudasaini, M. P., Viaene, N., \& Moens, M. (2006b). Effect of marigold (Tagetes patula) on population dynamics of Pratylenchus penetrans in a field. Nematology, 8, 477-484.

Sato, E., Min, Y. Y., Toyota, K., \& Takada, A. (2009). Relationships between the damage to radish caused by the root-lesion nematode Pratylenchus penetrans, its density prior to cultivation and the soil nematode community structure evaluated by polymerase chain reaction-denaturing gradient gel electrophoresis. Soil Science and Plant Nutrition, $55,478-484$.

Schomaker, C. H., \& Been, T. H. (2013). Plant growth and population dynamics. In R. N. Perry \& M. Moens (Eds.), Plant nematology (2nd ed., pp. 301-330). Wallingford: CAB International.

Seinhorst, J. W. (1966). The relationships between population increase and population density in plant-parasitic nematodes I. Introduction and migratory nematodes. Nematologica, 12, $157-169$.

Seinhorst, J. W. (1967). Review of methods for measuring damage caused by nematodes. FAO, Symposium on crop losses, Rome, Italy.

Seinhorst, J. W. (1970). Dynamics of populations of plant parasitic nematodes. Annual Review of Phytopathology, 8, 131-156.
Seinhorst, J. W. (1988). The estimation of densities of nematode populations in soil and plants. Vaxtskyddsrapporter jordbruk, pp. $43-68$.

Seinhorst, J. W. (1998). The common relation between population density and plant weight in pot and micro plot experiments with various nematode plant combinations. Fundamental and Applied Nematology, 21, 459-468.

Stein, W. (1963). Untersuchungen über den Befall von Möhren durch Meloidogyne hapla Chitwood in zwei aufeinanderfolgenden Anbaujahren. Zeitschrift Pflanzenpathologie und Pflanzenschutz, 70, 217-223.

Teklu, M. G., Schomaker, C. H., \& Been, T. H. (2014). Relative susceptibilities of five fodder radish varieties (Raphanus sativus var. oleiformis) to Meloidogyne chitwoodi. Nematology, 16, 577-590.

Viaene, N. M., \& Abawi, G. S. (1996). Damage threshold of Meloidogyne hapla to lettuce in organic soil. Journal of Nematology, 28, 537-545.

Vrain, T. C., \& Belair, G. (1981). Symptoms induced by the lesion nematode, Pratylenchus penetrans on carrot taproots in organic soil. Phytoprotection, 62, 79-81.

Walker, G. E. (2004). Associations between carrot defects and nematodes in South Australia. Australasian Plant Pathology, 33, 579-584.

Weischer, B., \& Brown, D. J. F. (2000). An introduction to nematodes: General nematology. A students' textbook. Pensoft,Sofia, Bulgaria, pp. 187.

Wesemael, W. M. L., \& Moens, M. (2008). Quality damage on carrots (Daucus carota L.) caused by the root-knot nematode Meloidogyne chitwoodi. Nematology, 10, 261270 . 